\title{
Selection of KYC 3270, a Cellulolytic Myxobacteria of Sorangium cellulosum, against Several Phytopathogens and a Potential Biocontrol Agent against Gray Mold in Stored Fruit
}

\author{
Sung-Taek Kim and Sung-Chul Yun* \\ Department of Biomedical Sciences, Sun Moon University, Asan 330-744, Korea \\ (Received on July 18, 2011; Revised on August 19, 2011; Accepted on August 20, 2011)
}

\begin{abstract}
During 2002-2008 in Korea, 455 extracts from myxobacteria consisting of 318 cellulolytic and 137 bacteriolytic myxobacteria were isolated, which were then screened for antifungal activity against the phytopathogens Botrytis cinerea, Colletotrichum acutatum, Penicillium sp., Pyricularia grisea, and Phytophthora capsici. 204 isolates had antifungal activity, causing both a clear zone due to blocked spore germination and inhibition of mycelial growth; most (199) were from cellulolytic (Sorangium cellulosum) and only five were from bacteriolytic myxobacteria. $B$. cinerea, the best controlled among the five tested pathogens, had a unique group of antifungal isolates of myxobacterial extracts compared to the other pathogens' groups. Among seventy-nine bioactive myxobacteria, four isolates, KYC 3130, KYC 3247 , KYC 3248 and KYC 3270, were selected and all were cellulolytic. Liquid culture filtrates of these four myxobacteria were applied to tomato, cherry tomato, strawberry, and kiwi fruits $5 \mathrm{~h}$ before inoculation with gray mold conidia; then the treated fruits were placed in an airtight container and the experiment was repeated six to eight times. Incidence (\%) of gray mold on fruit of the infected control treatment was $84-98 \%$, whereas it was only $5-21 \%$ after the KYC 3270 treatment. After KYC 3270 treatment of the four fruits, mold control was $79-95 \%$, which was highest among the filtrates and statistically the same as treatment with fludioxonil, a registered chemical against gray mold of stored fruits.
\end{abstract}

Keywords : antifungal activity, Botrytis cinerea, cellulolytic myxobacteria, strawberry

Myxobacteria have a fruiting body with bacteriolytic or cellulolytic characteristics (Cho, 2001; Dawid, 2000; Kim and Son, 2001; Kim et al., 2003a). The cellulolytic myxobacteria are able to degrade cellulose, grow well, and can be isolated in culture medium containing cellulose. So far, two

\footnotetext{
*Corresponding author.

Phone) +82-41-530-2282, FAX) +82-41-530-2939

E-mail)scyun@sunmoon.ac.kr
}

species of cellulolytic myxobacteria are known, Sorangium cellulosum and Byssovorax cruenta (Reichenbach, 2001). $S$. cellulosum produces more than 30 different bioactive metabolites, including ambruticin, chivosalzole, disorazole, eliamid, epothilone, etnangien, jerangolid, ratjadon, socein, sorangicin, soraphen, spirodienal, spirangien, and tartrolon, which comprise $48 \%$ of the bioactive metabolites of myxobacteria (Dawid, 2000; Gerth et al., 2003; Niggemann et al., 2002).

Most bioassays for biological activity of myxobacteria have been with bacteriolytic myxobacteria such as Myxococcus spp. (Ahn and Kim, 2002; Bull et al., 2002; Chung et al., 2008; Kim and Yun, 2011; Kim et al., 1998; Kim et al., 2003b; Krug et al., 2008), although the antifungal activity of $S$. cellulosum, a cellulolytic myxobacterium, against several phytopathogenic fungi has been examined in Germany (Reichenbach and Höfle, 1994). Soraphen and epothilone are two natural products of S. cellulosum, and soraphen in particular is an antifungal compound. In field trials, this compound completely inhibited apple scab fungi (Venturia inaequalis) and also prevented grape gray mold (Botrytis cinerea) (Reichenbach and Höfle, 1994). According to the paper disk method for dual culture, Spirodienal C, new metabolites from $S$. cellulosum, have antifungal activity against B. cinerea, Botryosphaeria dothidea, and Sclerotinia sclerotiorum (Ahn, 2009). Hence, such a cellulolytic myxobacterium has extraordinary ability to produce secondary metabolites with biological activity (Gerth, 2003); however, more cellulolytic myxobacteria containing similar natural products have yet to be studied.

$B$. cinerea is a phytopathogen on more than 200 species under humid and low temperature conditions during storage (Hang et al., 2005; Kulakiotu et al., 2004; Tian et al., 2002; Williamson et al., 2007). To control B. cinerea in Korean fields, many fungicides having different modes of action were developed, e.g., benzimidazole, dicarboximide, sulfamide, $N$-phenylcarbamate, phenylpyrrol, and anilinopyrimidine (Choi et al., 1999, 2009a). However, A B. cinerea resistance to benzimidazole through a change of amino acid residue in $\beta$-tubulin was discovered (Soung and Sung, 
2007). A new procymidone fungicide was developed but this led to several new $B$. cinerea strains with single and multiple resistances (Lee et al., 2007). Because $B$. cinerea is able to change during hyphal fusion, genetic changes are frequent, often leading to resistance to fungicides (Choi et al., 1995). If an edible product such as strawberry contains fungicide residues, this leads to public concern, which has thus accelerated the search for alternative control strategies against gray mold, e.g., biological controls (Hjeljord et al., 2001).

For biological control of $B$. cinerea, Acremonium strionum (Choi et al., 2009b), Bacillus spp. (Hang et al., 2005; Kim et al., 2007; Park et al., 2006; Son et al., 2002), Pseudomonas spp. (Sharma et al., 2009), Trichoderma harzianum (Hjeljord et al., 2002; O'Neill et al., 1996), Ulocladium atrum (Boff et al., 2002; Lee et al., 2004), and natural volatiles (Kulakiotu et al., 2004) have been applied. The biopesticide for $B$. cinerea control, Trichodex ${ }^{\circledR}$, is a commercial product from $T$. harzianum containing an enzyme that dissolves the fungal cell wall and competes for nutrients with the pathogen. One can also delay $B$. cinerea conidial germination and prevent infection into host tissues (Paulitz and Bélanger, 2001).

Since myxobacteria are producing unique secondary metabolites as earlier mention, their biological activity could provide alternative biocontrol agents against gray mold in various storage fruits, thus reducing the need for chemical treatments. Biocontrol activity against gray mold by $S$. cellulosum, a cellulolytic myxobacterium, has never been investigated on stored fruits such as strawberry, tomato, and kiwi. We screened 455 myxobacteria from Korean soil for antifungal activity against several phytopathogens including $B$. cinerea, and compared antifungal activity against gray mold among the selected cellulolytic myxobacteria, KYC 3130, KYC 3247, KYC 3248 and KYC 3270, on tomato, cherry tomato, strawberry and kiwi.

\section{Materials and Methods}

Myxobacterial extracts. In total, 455 myxobacterial extracts were obtained from Myxobank, which had been isolated from South Korean soils between 2002 and 2008. Among these, 318 were cellulolytic and the rest were bacteriolytic myxobacteria. All 318 cellulolytic myxobacteria were identified as $S$. cellulosum, while the 137 isolates of bacteriolytic myxobacteria were identified as Myxococcus spp., Corallococcus spp., Stigmatella spp., and Citrobacter sp. (Fig. 1). S. cellulosum extracts were prepared with ST21CXP medium (Hyun et al., 2009), and extracts of bacteriolytic myxobacteria were prepared with WCX medium and E. coli as feedstock (Park et al., 2004). Either ST21CXP or WCX medium was used for the

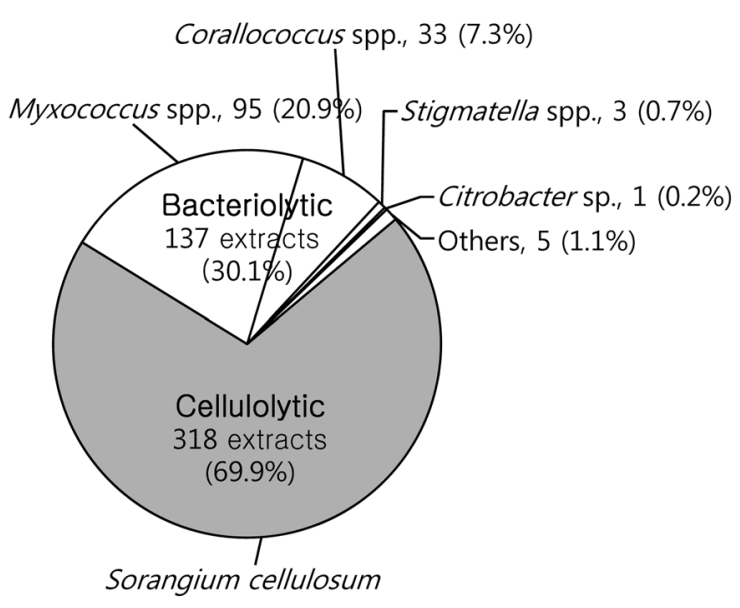

Fig. 1. The profile of 455 myxobacterial extracts screened for antifungal activity from Myxobank. The only species of cellulolytic myxobacterium among 318 extracts was Sorangium cellulosum. The species of bacteriolytic myxobacteria in the other 137 extracts included Myxococcus spp., Corallococcus spp., Stigmatella spp., and Citrobacter sp., among others.

development of fruiting bodies, and crystals were obtained from $50 \mathrm{ml}$ of liquid medium. The crystals were dissolved in dimethyl sulfoxide (DMSO) to obtain $1 \mathrm{ml}$ of myxobacterial extract.

Phytopathogens. The fungal pathogens $B$. cinerea (no. 43528), Pyricularia grisea (no. 40420), and an oomycete pathogen, Phytophthora capsici (no. 40476), were obtained from the Korean Agricultural Culture Collection (KACC). Colletotrichum acutatum SM017 was isolated from fieldgrown hot pepper at Asan, Chungnam; Penicillium sp. was isolated from a diseased orange.

Antagonism to mycelial growth and conidial germination in vitro. A dual culture assay for antagonism was conducted on potato dextrose agar (PDA, Difco, Sparks, MD) (24 g potato dextrose, $15 \mathrm{~g}$ agar per liter) against the phytopathogens $B$. cinerea, P. capsici, C. acutatum, Penicillium sp., and $P$. grisea with antagonistic myxobacterial extracts for 7, 7, 10, 12, and 12 days, respectively. Mycelial agar plugs of $5 \mathrm{~mm}$ diameter of the five pathogens were placed in the middle of the PDA medium; then $12 \mu \mathrm{l}$ of myxobacterial extract was put on the mycelia for 4-8 days at $25^{\circ} \mathrm{C}$ and mycelial growth measured. Each replication consisted of three plates. Except for $P$. capsici, the clear zone around conidia $B$. cinerea, $C$. acutatum, Penicillium sp., and $P$. grisea was examined to assess blocking of germination by myxobacterial extracts. A conidial suspension of $P$. grisea was cultured in oatmeal agar (Difco, Sparks, MD) and the other three fungi were cultured in PDA. The conidial suspensions were adjusted to $1 \times 10^{5}$ 
conidia/ml. To test for germination, a $25 \mu \mathrm{l}$ conidial suspension of each fungus was smeared on PDA plates, then an 8-mm paper disk with $12 \mu \mathrm{l}$ myxobacterial extract was placed in the middle of the culture and incubated in darkness for 4 days at $25^{\circ} \mathrm{C}$. The control was $12 \mu \mathrm{l}$ DMSO on an 8-mm paper disk for each fungal culture. The diameter of the clear zone (no conidial germination) was measured. Among the tested myxobacterial extracts, those with the best antifungal activity were selected based on least mycelial growth and largest clear zone.

Cellulolytic myxobacteria. Based on mycelial growth and spore germination, four cellulolytic myxobacteria, KYC 3270, KYC 3248, KYC 3247 and KYC 3130 were selected. KYC 3270 and 3248 were isolated from soil at Gimcheon, Gyeongbuk, in 2008; KYC 3247 was isolated from soil at Hadong, Gyeongnam, in 2008; and KYC 3130 was isolated from soil at Hwacheon, Gangwon, in 2007. All were obtained from Myxobank [http://www.myxobank.or.kr/]. To compare antifungal activity between cellulolytic and bacteriolytic myxobacteria, Myxococcus sp. KYC 1126 with antagonistic activity against pepper anthracnose (Kim and Yun, 2011) was also cultured and applied as a liquid filtrate. The four cellulolytic myxobacteria were cultured on ST21P agar medium $\left(1 \mathrm{~g} \mathrm{~K}_{2} \mathrm{HPO}_{4}, 0.02 \mathrm{~g}\right.$ yeast extract, $1 \mathrm{~g} \mathrm{KNO}_{3}, 1 \mathrm{~g} \mathrm{MgSO}_{4} \cdot 7 \mathrm{H}_{2} \mathrm{O}, 0.2 \mathrm{~g} \mathrm{FeCl}_{3}$, $0.1 \mathrm{~g} \mathrm{MnSO}_{4} \cdot 7 \mathrm{H}_{2} \mathrm{O}, 15 \mathrm{~g}$ agar per liter) with the mycobiont on filter paper (Avantec no. 1, Toyo Roshi Kaisha, Japan) for 7 days at $32^{\circ} \mathrm{C}$. In addition, $1 \mathrm{ml}$ of microelements $(100$ $\mathrm{mg} \mathrm{MnCl}_{2} \cdot 4 \mathrm{H}_{2} \mathrm{O}, 20 \mathrm{mg} \mathrm{CoCl}, 10 \mathrm{mg} \mathrm{CuSO}$, $10 \mathrm{mg}$ $\mathrm{Na}_{2} \mathrm{MoO}_{4} \cdot 2 \mathrm{H}_{2} \mathrm{O}, 20 \mathrm{mg} \mathrm{ZnCl}$, $5 \mathrm{mg} \mathrm{LiCl}, 5 \mathrm{mg}$ $\mathrm{SnCl}_{2} \cdot 2 \mathrm{H}_{2} \mathrm{O}, 10 \mathrm{mg} \mathrm{H}_{3} \mathrm{BO}_{3}, 20 \mathrm{mg} \mathrm{KBr}, 20 \mathrm{mg} \mathrm{KI}, 8 \mathrm{mg}$ EDTA, Na-Fe ${ }^{3+}$ salt (trihydrate) per liter; Hyun et al., 2009) was added to $11 \mathrm{ST} 21 \mathrm{P}$ agar medium.

To produce antifungal material from the myxobacteria in liquid culture, the cell-cultured filter paper was inoculated in CSG/1 liquid medium $(0.5 \mathrm{~g}$ glucose, $3 \mathrm{~g}$ soluble starch, $1 \mathrm{~g}$ raffinose, $2 \mathrm{~g}$ casitone, $0.5 \mathrm{~g} \mathrm{MgSO}_{4} \cdot 7 \mathrm{H}_{2} \mathrm{O}, 1 \mathrm{~g}$ $\mathrm{CaCl}_{2} \cdot 2 \mathrm{H}_{2} \mathrm{O}, 0.25 \mathrm{~g} \mathrm{~K}_{2} \mathrm{HPO}_{4}, 0.5 \mathrm{mg}$ vitamin $\mathrm{B}_{12}, 4 \mathrm{ml}$ microelement solution per liter) for 7 days at $32{ }^{\circ} \mathrm{C}$, with shaking at $180 \mathrm{rpm}$. The microelement solution for CSG/1 liquid medium was $10 \mathrm{ml} \mathrm{H}_{2} \mathrm{SO}_{4}, 14.6 \mathrm{~g} \mathrm{FeCl}_{3} \cdot 6 \mathrm{H}_{2} \mathrm{O}, 2 \mathrm{~g}$ $\mathrm{ZnCl}_{3}, 1 \mathrm{~g} \mathrm{MnCl}_{2} \cdot 4 \mathrm{H}_{2} \mathrm{O}, 0.43 \mathrm{~g} \mathrm{CuCl}_{2} \cdot 2 \mathrm{H}_{2} \mathrm{O}, 0.31 \mathrm{~g} \mathrm{H}_{3} \mathrm{BO}_{3}$, $0.24 \mathrm{~g} \mathrm{CaCl}_{2} \cdot 6 \mathrm{H}_{2} \mathrm{O}, 0.24 \mathrm{~g} \mathrm{Na}_{2} \mathrm{MoO}_{4} \cdot 2 \mathrm{H}_{2} \mathrm{O}$ per liter (Hyun et al., 2009). For long-term maintenance, the mycobiont of the cellulolytic myxobacteria was prepared on filter paper on ST21P medium. The fruiting body of the cellulolytic myxobacteria was dried in a tube for 2 days in a desiccator, then put in a freezer at $-70{ }^{\circ} \mathrm{C}$. The preserved culture was revived when needed.

Bioassays of myxobacterial filtrates on fruit. A bioassay for antifungal activity of the four cellulolytic myxobacteria (KYC 3270, KYC 3248, KYC 3247, and KYC 3130) and bacteriolytic myxobacterium (KYC 1126) was conducted on strawberry, tomato, cherry tomato, and kiwi. The surface of treated fruits was first sterilized with $1 \%$ sodium hypochlorite for $2 \mathrm{~min}$, washed twice with sterilized water, then dried. Culture filtrates of the four cellulolytic and one bacteriolytic myxobacterium without dilution were sprayed on fruit until the filtrate ran off. To compare activity against gray mold on the stored fruit, the commercial fungicide fludioxonil was selected as a positive control and sprayed with $0.5 \mathrm{mg} / \mathrm{ml}$. Fludioxonil (a.i. $20 \%$, SC) is known to inhibit mycelial growth and spore germination. The treated fruits were dried for $5 \mathrm{~h}$ at $4{ }^{\circ} \mathrm{C}$, and then $1 \times 10^{5}$ conidia/ml suspension was inoculated onto treated fruits, which were placed in a container with $100 \% \mathrm{RH}$ by adding $20 \mathrm{ml}$ distilled water on paper towel at $22{ }^{\circ} \mathrm{C}$ for $5-11$ days, depending on the fruit.

Strawberry, tomato, and cherry tomato were inoculated with conidial suspensions of gray mold without any wounding, while kiwi was inoculated with a syringe needle at two wounds per fruit. Bioassay of strawberry, tomato, cherry tomato, and kiwi was replicated $6,8,8$, and 7 times, respectively. Gray mold on strawberry, tomato, and cherry tomato was observed at 3,4 , and 5 days after inoculation; disease of kiwi was checked using fruit cross-sections 11 days after inoculation. The incidence of gray mold and control value for the myxobacterium as well as the fungicide were determined as follows:

Gray mold incidence $(\%)=$ No. of diseased fruits/Total no. of treated fruits $\times 100$

Control value $(\%)=$ (Incidence on untreated plot Incidence on treated plot)/(Incidence on untreated plot) $\times 100$

Statistical multiple comparisons to the control values among the tested myxobacterial isolates and fludioxonil were analyzed with Fisher's least significant difference (LSD) test at a specified value of $\alpha<0.05$.

\section{Results}

Myxobacterial extracts with antifungal activity. The myxobacterial extracts that completely inhibited mycelial growth and produced a clear zone by blocking germination were considered to have most antifungal activity (Fig. 2). Depending on the pathogen, the number of extracts with antifungal activity differed. Of 318 cellulolytic extracts, 74 , 53,43 , and 29 extracts had antagonistic activity against $B$. cinerea, P. grisea, Penicillium sp., and $C$. acutatum, respectively (Fig. 2A). Of 137 bacteriolytic extracts, only five had antifungal activity specifically against $B$. cinerea (Fig. 2B). 


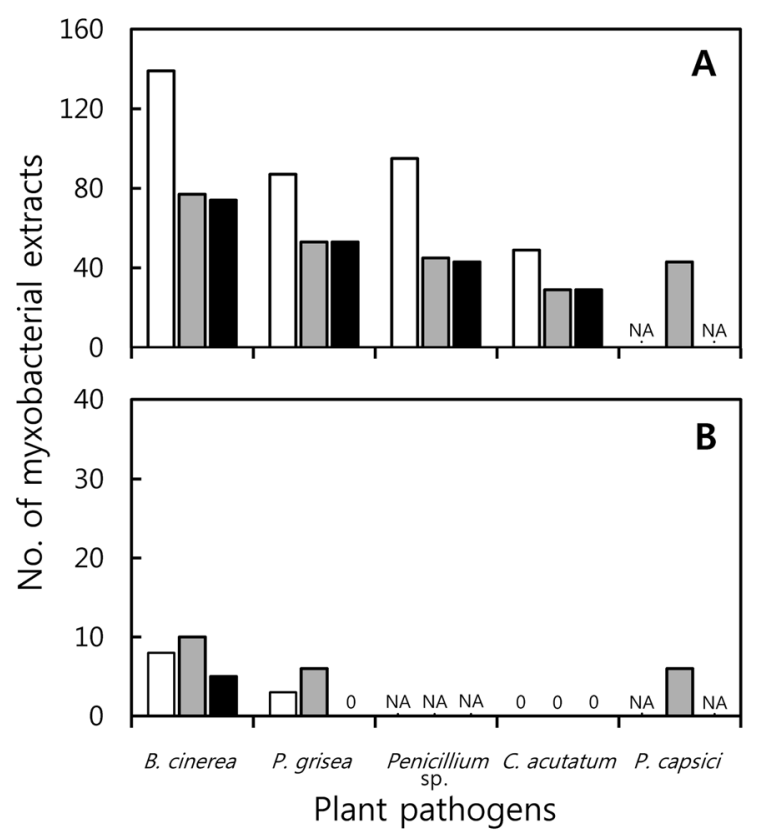

Fig. 2. The number of extracts showing an antifungal activity among 318 cellulolytic (A) and 137 bacteriolytic (B) myxobacterial types against five phytopathogens. The antifungal activity on dual culture was to be seen as a clear zone $(\square)$ due to inhibition of conidial germination or complete lack of mycelial growth $(\square)$. Isolates $(\square)$ that simultaneously showed a clear zone and mycelial growth inhibition. The tested five pathogens were Botrytis cinerea, Pyricularia grisea, Penicillium sp., Colletotrichum acutatum, and Phytophthora capsici. Inhibition of zoospore germination of $P$. capsici and a bioassay of bacteriolytic myxobacteria against Penicillium sp. were not conducted.

The cellulolytic myxobacteria had much more antifungal activity than the bacteriolytic myxobacteria, and $B$. cinerea was the most affected pathogen in these tests. Among 77 extracts that completely inhibited $B$. cinerea mycelial growth, 74 blocked both $B$. cinerea germination and inhibited mycelial growth. Therefore, most extracts inhibited mycelial growth and blocked conidial germination in all pathogens examined (Fig. 2A). None of the 137 bacteriolytic myxobacteria extracts blocked C. acutatum conidial germination or completely inhibited its mycelial growth (Fig. 2B).

Antifungal effect on mycelial growth and spore germination of phytopathogens. The effect of the antagonists on mycelial growth could be divided into three levels: complete, delayed, and non-inhibition (Table 1). Among the 318 cellulytic myxobacterial extracts, about half had no antifungal activity, and delayed growth was little better than that of the complete level. However, the mycelial growth of C. acutatum was different: $44 \%$ was non-inhibited, $47 \%$ was delayed, and only $9 \%$ was completely inhibited. Among 137 bacteriolytic myxobacterial extracts, 115 extracts did not inhibit mycelial growth of B. cinerea, $7 \%$ completely inhibited mycelial growth, and $10 \%$ delayed growth of of B. cinerea. Whereas 134 extracts didn't inhibit mycelial growth of $C$. acutatum, $0 \%$ completely inhibited the mycelial growth, and $2 \%$ delayed growth of $C$. acutatum.

Blocking of spore germination, as shown by a clear zone, was divided into five levels according to size (Table 1). Of 318 cellulolytic myxobacterial extracts, $53-85 \%$ of the 287 cellulolytic myxobacterial extracts tested against the four pathogens had no clear zone (Table 1). At best, $10 \%$ had clear zones of more than $30 \mathrm{~mm}$ against $B$. cinerea, which was the most inhibited fungus. Among the tested 137

Table 1. The number of myxobacterial extracts with antifungal activity against the five phytopathogens Botrytis cinerea, Colletotrichum acutatum, Pyricularia grisea, Penicillium sp., and Phytophthora capsici. Antifungal activity was assessed as the inhibition of mycelial growth and a clear zone due to blocking of spore germination of the pathogens

\begin{tabular}{|c|c|c|c|c|c|c|c|c|c|}
\hline \multirow{2}{*}{$\begin{array}{c}\text { Myxobacterial } \\
\text { type }\end{array}$} & \multirow[b]{2}{*}{ Pathogen } & \multicolumn{3}{|c|}{ Inhibition of mycelial growth } & \multicolumn{5}{|c|}{ Clear zone due to blocking of spore germination } \\
\hline & & $\begin{array}{l}\text { Complete } \\
\text { inhibition }\end{array}$ & $\begin{array}{l}\text { Delayed } \\
\text { growth }\end{array}$ & Non-inhibition & $\begin{array}{l}>30 \\
\mathrm{~mm}\end{array}$ & $\begin{array}{c}20-30 \\
\mathrm{~mm}\end{array}$ & $\begin{array}{c}10-20 \\
\mathrm{~mm}\end{array}$ & $\begin{array}{l}<10 \\
\mathrm{~mm}\end{array}$ & None \\
\hline \multirow{5}{*}{ Cellulolytic } & B. cinerea & $77 / 318^{a}$ & $71 / 318$ & $170 / 318$ & $36 / 318$ & $35 / 318$ & $59 / 318$ & $9 / 318$ & $179 / 318$ \\
\hline & C. acutatum & $29 / 318$ & $149 / 318$ & $140 / 318$ & $0 / 318$ & $5 / 318$ & $41 / 318$ & $3 / 318$ & $269 / 318$ \\
\hline & P. grisea & $53 / 318$ & $87 / 318$ & $178 / 318$ & $40 / 318$ & $22 / 318$ & $25 / 318$ & $0 / 318$ & $231 / 318$ \\
\hline & Penicillium sp. $^{\mathrm{b}}$ & $45 / 287$ & $58 / 287$ & $184 / 287$ & $16 / 287$ & $32 / 287$ & $32 / 287$ & $15 / 287$ & $192 / 287$ \\
\hline & P. capsici & $43 / 318$ & $65 / 318$ & $210 / 318$ & $\mathrm{NA}^{\mathrm{c}}$ & NA & NA & NA & NA \\
\hline \multirow{4}{*}{ Bacteriolytic } & B. cinerea & $10 / 137$ & $12 / 137$ & $115 / 137$ & $0 / 137$ & $0 / 137$ & $6 / 137$ & $2 / 137$ & $129 / 137$ \\
\hline & C. acutatum & $0 / 137$ & $3 / 137$ & $134 / 137$ & $0 / 137$ & $0 / 137$ & $0 / 137$ & $0 / 137$ & $137 / 137$ \\
\hline & P. grisea & $6 / 137$ & $14 / 137$ & $117 / 137$ & $0 / 137$ & $0 / 137$ & $1 / 137$ & $2 / 137$ & $134 / 137$ \\
\hline & P. capsici & $6 / 137$ & $12 / 137$ & $119 / 137$ & NA & NA & NA & NA & NA \\
\hline
\end{tabular}

${ }^{a}$ Number of myxobacterial isolates showing each character among the tested isolates.

${ }^{\mathrm{b}}$ Due to a shortage of extracts, some isolates of myxobacteria were not tested against Penicillium sp.

${ }^{\mathrm{c}} \mathrm{NA}$, not tested for blocking the germination of zoospores of $P$. capsici. 
Table 2. Number of myxobacterial isolates with multiple antifungal activity on two phytopathogens simultaneously. Antifungal activity was the number of myxobacterial extracts that caused both inhibition of mycelial growth and a clear zone due to blocking conidial germination of the pathogen. The percentages in the parenthesis are proportion of extracts

\begin{tabular}{lccccc}
\hline \hline \multirow{2}{*}{ Pathogens } & \multirow{2}{*}{$\begin{array}{c}\text { Antifungal } \\
\text { activity }\end{array}$} & \multicolumn{3}{c}{ No. of extracts with antifungal activity against two pathogens } \\
\cline { 3 - 6 } & $79^{\mathrm{a}}$ & B. cinerea & P. grisea & Penicillium sp. & C. acutatum \\
\hline B. cinerea & $53^{\mathrm{b}}$ & $17(32 \%)$ & $17(22 \%)$ & $14(18 \%)$ & $7(9 \%)$ \\
P. grisea & $43^{\mathrm{b}}$ & $14(26 \%)$ & $27(63 \%)$ & $27(51 \%)$ & $29(55 \%)$ \\
Penicillin $\mathrm{sp}$. & $29^{\mathrm{b}}$ & $7(24 \%)$ & $29(100 \%)$ & - & $23(54 \%)$ \\
C. acutatum & & $7(79 \%)$ & - \\
\hline
\end{tabular}

${ }^{a}$ Extracts with antifungal activity against $B$. cinerea consisted of 74 cellulolytic and five bacteriolytic myxobacteria.

${ }^{\mathrm{b}}$ The extracts with antifungal activity against each pathogen were all cellulolytic myxobacteria.

extracts of bacteriolytic myxobacteria, eight and three extracts blocked conidial germination of $B$. cinerea and $P$. grisea, respectively, with clear zones of $20 \mathrm{~mm}$ or less (Table 1). None of the 137 extracts inhibited C. acutatum conidial germination.

Multiple antifungal activity of myxobacterial extracts on the four phytopathogens. Some myxobacterial extracts had antifungal activity against more than one phytopathogen. Several extracts had antifungal activity simultaneously against two phytopathogenic fungi out of the four $(B$. cinerea, P. grisea, Penicillium sp., and C. acutatum; Table 2). Of the 79 extracts with antifungal activity against $B$. cinerea, 74 were cellulolytic and five were bacteriolytic myxobacteria. Among these, 17 shared antifungal activity against $P$. grisea and 14 shared it against Penicillium sp. All extracts with antifungal activity against $C$. acutatum also had antifungal activity against the combination $C$. acutatum$P$. grisea. Combinations with $B$. cinerea, for example, with P. grisea, Penicillium sp., or C. acutatum, had antifungal activity of $9-32 \%$. However, combinations without $B$. cinerea, for example, $P$. grisea with Penicillium sp. or $C$. acutatum, Penicillium sp. with $P$. grisea or $C$. acutatum, $C$. acutatum with $P$. grisea or Penicillium sp., had antifungal activity of $51-100 \%$ (Table 2).

Some myxobacterial extracts had antifungal activity against more than three pathogens simultaneously (Table
3). Twenty-three extracts had antifungal activity against $C$. acutatum, P. grisea, and Penicillium sp. simultaneously. KYC 3019, KYC 3188, KYC 3189 and KYC 3204 had antifungal activity against four pathogens tested. Clear zones against $C$. acutatum $(14.5-21.4 \mathrm{~mm})$ and $P$. grisea $(32.7-37.1 \mathrm{~mm})$ depended on the isolate, and those against B. cinerea were $12.1-18.3 \mathrm{~mm}$. Despite 79 extracts having strong antifungal activity against $B$. cinerea, only four to seven extracts shared antifungal activity with other pathogens; hence, little antifungal activity against $B$. cinerea was shared among the other three pathogens.

Bioassay of selected myxobacteria against gray mold on stored fruit. After 3, 4 and 5 days of inoculation with gray mold conidial spraying, disease incidences on strawberry (Fig. 3A), tomato (Fig. 3B), and cherry tomato (Fig. 3C) were examined. The incidence of gray mold in the nontreated control was almost $100 \% 5$ days after inoculation, while the incidence on kiwi (Fig. 3D) was about $80 \% 11$ days after wound inoculation. Multiple comparisons among the tested isolates were conducted only on the final day of examination. The lowest disease incidence among the filtrate treatments was with KYC 3270 on all four fruits. This was statistically the same as the positive control with fludioxonil, and was significantly lower than any of the other tested myxobacteria isolates. Disease incidences after treatment with KYC 3248, KYC 3247, or KYC 3130, were

Table 3. Number of myxobacterial isolates with multiple antifungal activity against more than three phytopathogens simultaneously. The isolates with antifungal activity against the listed pathogen inhibited mycelial growth and produced a clear zone due to blocking spore germination of the pathogens in dual culture

\begin{tabular}{cc}
\hline \hline Pathogens & $\begin{array}{c}\text { No. of extracts with antifungal activity against } \\
\text { more than } 3 \text { phytopathogens }\end{array}$ \\
\hline B. cinerea + C. acutatum + P. grisea & 7 \\
B. cinerea + C. acutatum + Pencillium $\mathrm{sp.}$ & 4 \\
B. cinerea + P. grisea + Pencillium $\mathrm{sp}$. & 4 \\
C. acutatum + P. grisea + Pencillium sp. & 23 \\
B. cinerea + C. acutatum + P. grisea + Pencillium $\mathrm{sp}$. & 4 \\
\hline
\end{tabular}




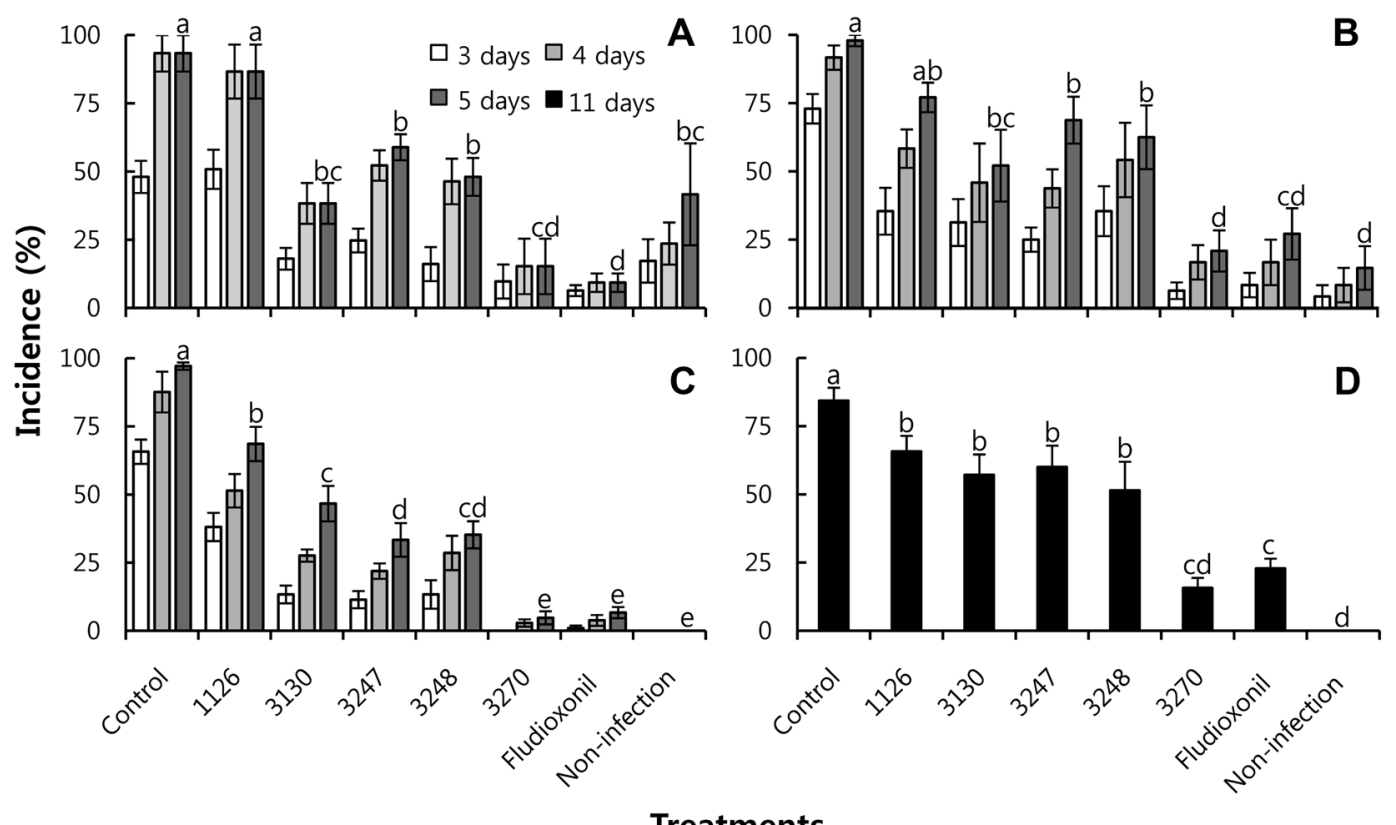

Fig. 3. Incidence of gray mold on strawberry (A), tomato (B), cherry tomato (C), and kiwi (D) in airtight boxes treated with culture filtrates of myxobacteria. Except for kiwi, the incidence was measured $3(\square), 4(\square)$, and $5(\square)$ days after inoculation. Data bars are averages of eight replicates and error bars are standard errors. The same letters represent values that are not statistically different according to the LSD (Fisher's least significant difference) test at $P<0.05$.

Table 4. Control values of the selected four cellulolytic and one bacteriolytic myxobacterium. Each value represents the average \pm standard error of six to eight replicates, depending on the fruit. The letter following is the result of multiple comparisons by LSD test $(p<0.05)$ among the treatments

\begin{tabular}{ccccccc}
\hline \hline \multirow{2}{*}{ Fruits } & \multicolumn{5}{c}{ Control value (\%) } \\
\cline { 2 - 7 } & fludioxonil $^{\mathrm{a}}$ & \multicolumn{1}{c}{ KYC 3270 $^{\mathrm{b}}$} & KYC 3248 & KYC 3247 & KYC 3130 $^{\mathrm{b}}$ & ${\text { KYC } 1126^{\mathrm{c}}}^{\mathrm{b}}$ \\
\hline Strawberry & $88.5 \pm 5.1 \mathrm{~d}$ & $84.7 \pm 10.2 \mathrm{~d}$ & $49.7 \pm 5.3 \mathrm{bc}$ & $36.7 \pm 3.0 \mathrm{~b}$ & $59.5 \pm 6.7 \mathrm{c}$ & $8.9 \pm 5.9 \mathrm{a}$ \\
Tomato & $72.5 \pm 9.4 \mathrm{c}$ & $79.2 \pm 7.6 \mathrm{c}$ & $35.4 \pm 12.4 \mathrm{~b}$ & $29.2 \pm 9.3 \mathrm{~b}$ & $46.2 \pm 13.5 \mathrm{~b}$ & $22.9 \pm 8.5 \mathrm{ab}$ \\
Cherry tomato & $93.1 \pm 2.1 \mathrm{~d}$ & $95.1 \pm 2.5 \mathrm{~d}$ & $63.8 \pm 5.2 \mathrm{c}$ & $65.2 \pm 6.9 \mathrm{c}$ & $51.8 \pm 7.0 \mathrm{c}$ & $29.5 \pm 6.3 \mathrm{~b}$ \\
Kiwi & $72.3 \pm 5.2 \mathrm{c}$ & $81.0 \pm 4.6 \mathrm{c}$ & $40.6 \pm 10.2 \mathrm{~b}$ & $28.2 \pm 9.4 \mathrm{~b}$ & $31.0 \pm 10.2 \mathrm{~b}$ & $20.3 \pm 8.5 \mathrm{ab}$ \\
\hline
\end{tabular}

${ }^{a} \mathrm{~A}$ fungicide against Batrytis cinerea.

${ }^{b}$ KYC 3270, KYC 3248, KYC 3247, and KYC 3130 are cellulolytic myxobacteria, i.e., Sorangium cellulosum.

${ }^{\mathrm{c}} \mathrm{KYC} 1126$ is a bacteriolytic myxobacterium, i.e., Myxococcus sp.

significantly lower than the infected control. Neither KYC1126, which was selected for anthracnose treatment (Kim and Yun, 2011), nor the bacteriolytic myxobacterium had antifungal activity on strawberry and tomato. Gray mold was found in negative controls (no artificial infection) on strawberry and tomato ( $41 \%$ and $15 \%$, respectively). In contrast, disease incidences after KYC 3270 and fludioxonil treatment were $15.3 \%$ and $9.3 \%$, respectively, and significantly less than the negative control. Therefore, KYC 3270 had a biological curative effect and fludioxonil had a chemical curative effect.

The control values of the four selected cellulolytic myxobacterial isolates were compared with a positive control, fludioxonil, and a bacteriolytic myxobacterial isolate (Table
4). Depending on the tested fruit, the control values of KYC 3270 isolates were $80-95 \%$, which is statistically the same as with fludioxonil; values for controls of the other three cellulolytic myxobacteria were about $30-60 \%$, which is statistically lower than in KYC 3270, while values for the bacteriolytic myxobacterium were $10-30 \%$. Treatment with cellulolytic myxobacterial filtrates gave the best control in cherry tomato, followed by strawberry, while kiwi was the least controlled.

\section{Discussion}

Among the tested 455 myxobacterial extracts, 204 had antifungal activity that totally inhibited mycelial growth 
and produced a clear zone by blocking spore germination on the tested phytopathogens. Only five bacteriolytic isolates out of these 204 had antifungal activity. Between $9 \%$ and $25 \%$ of 318 cellulolytic myxobacteria completely inhibited mycelial growth, depending on the pathogen, whereas only 0 to $7 \%$ of 137 bacteriolytic myxobacteria inhibited growth. In addition, the percentage of extracts that caused clear zones due to inhibited spore germination of three or four fungi was $15-44 \%$ for cellulolytic but only 0 $6 \%$ for bacteriolytic myxobacteria. Although most research on bioactivity has been conducted on bacteriolytic myxobacteria (Bull et al., 2002; Chung et al., 2008; Kim et al., 1998; Kim et al., 2003b; Krug et al., 2008; Kim and Yun, 2011), more cellulolytic myxobacteria should be studied because they have superior antifungal activity to bacteriolytic myxobacteria.

Among the five tested phytopathogens, $B$. cinerea was the best controlled with 455 myxobacterial extracts. The clear zone due to blocking of $B$. cinerea spore germination was wider and inhibition of mycelial growth larger than with the other tested pathogens. Four isolates had antifungal activity against all tested phytopathogens, including $B$. cinerea, although over 70 cellulolytic myxobacteria produced a larger clear zone than these four isolates. Hence, the selection of myxobacterial isolates should best be against a targeted fungus (e.g., B. cinerea) rather than a spectrum-wide test against several pathogens. The antifungal group of isolates against $B$. cinerea differed from those for the other three fungi, while the groups of isolates against the other fungi were shared. Note that all 27 selected isolates with antifungal activity against $C$. acutatum also had antifungal activity against $P$. grisea.

In this experiment, KYC 3270 produced a 38-mm clear zone in $B$. cinerea mycelium; it controlled more than $95 \%$ gray mold on cherry tomato and $79-85 \%$ on strawberry, tomato, and kiwi. Park et al. (2006) reported that Bacillus spp. have anti-gray mold activity, with a $26-\mathrm{mm}$ clear zone in dual culture; Bacillus licheniformis and B. megaterium, which were selected among 250 isolates, made $35-\mathrm{mm}$ and 37-mm clear zones in B. cinerea and controlled $95 \%$ and $91 \%$ of gray mold, respectively, on green perilla (Son et al., 2002); a wettable powder formulation of B. subtilis from a strawberry leaf controlled $92.9 \%$ of gray mold on strawberry, and Acremonium strictum controlled $88 \%$ of gray mold on tomato (Choi et al., 2009b). The level of antifungal activity of $S$. cellulosum KYC 3270 against gray mold was similar to the previously tested Bacillus spp. and A. strictum.

Gerth et al. (2003) reported that Soraphen, a material developed from $S$. cellulosum, inhibited growth of $B$. cinerea, while Ahn (2009) showed that Spirodienal C, produced from $S$. cellulosum, inhibited mycelial growth of $B$. cinerea, B. dothidea, and $S$. sclerotiorum but did not inhibit mycelial growth of C. acutatum, P. capsici, R. solani, Fusarium oxysporum, or Pythium ultimum. However, liquid filtrates of $S$. cellulosum KYC 3270 not only completely inhibited $B$. cinerea, but also $C$. acutatum, $P$. capsici, $P$. grisea, and Penicillium sp. We expect that the filtrate of KYC3270 contains at least 10 bioactive components, including Soraphen and Spirodienal C. In the future, KYC 3270 should be further analyzed. KYC 1126, which had no antifungal activity on $B$. cinerea, but was effective on $C$. acutatum (Kim and Yun, 2011), is also worthy of further study and should be compared with KYC 3270.

Since $B$. cinerea can latently infect fruits before harvest and produce conidia during storage or transport, infected fruits can become inocula for other fruits (Sharma et al., 2009). Selecting a biocontrol agent that has both preventive and curative effects after harvest is important. Two studies have reported that the curative effect of a biological agent is much less than the preventive effect (Choi et al., 2009b; Kim et al., 2007), although another reported that the preventive and curative effects of a biological agent are the same (Son et al., 2002). Because the filtrates were applied at least $12 \mathrm{~h}$ before inoculation with gray mold, antifungal activity of the tested isolates was focused on the preventive effect. A curative effect of KYC 3270 could be speculated from the strawberry bioassays, in which a $41.7 \%$ incidence in the negative control without $B$. cinerea inoculation suggests that the prepared strawberries were already infected. KYC 3270 inhibited B. cinerea mycelial growth and conidial germination, having both preventive and curative effects in the control of gray mold latent infection.

Even in developed countries, $20-25 \%$ of harvested fruit and vegetables are lost to postharvest pathogens (Sharma et al., 2009). Synthetic fungicides are used to control postharvest disease (El-Ghaouth, 2001), but safer and eco-friendly alternatives can provide better and more acceptable control. To enhance the bioefficacy of our selected myxobacterium requires consideration. First, the storage conditions (e.g., relative humidity, gas combination, and low temperature) should be examined. Second, our myxobacterium KYC 3270 should be further studied in mixtures; success in the control of gray mold with a mixture of Aureobasidium pullulans and Bacillus subtilis has been reported (Leibinger et al., 1997). Finally, salts, such as sodium bicarbonate, have been reported to enhance the control of gray mold on tomato (Xi and Tian, 2005). Thus, myxobacteria plus a salt may provide even better control of gray mold.

\section{References}

Ahn, J. W. 2009. Spirodienal C, a new spiroketal produced by Sorangium cellulosum (Myxobacteria). Bull. Kor. Chem. Soc. 30:1218-1220. 
Ahn, J. W. and Kim, B. S. 2002. Isolation and in vivo activities of antifungal compounds from Myxococcus sp. JW154 (Myxobacteria). Kor. J. Microbiol. Biotechnol. 30:162-166.

Boff, P., Köhl, J., Jansen, M., Horsten, P. J. F. M., Lombaers-van der Plas, C. and Gerlagh, M. 2002. Biological control of gray mold with Ulocladium atrum in annual strawberry crops. Plant Dis. 86:220-224.

Bull, C. T., Shetty, K. G. and Subbarao, K. V. 2002. Interactions between myxobacteria, plant pathogenic fungi, and biocontrol agents. Plant Dis. 86:889-896.

Cho, K. Y. 2001. Social behavior, fruiting body development, and bioactive metabolite production of myxobacteria. Kor. J. Bioindustry News. (in Korean) 14:11-16.

Choi, G. J., Kim, H. T., Kim, J. C. and Cho, K. Y. 1999. Antifungal activities of sulphamide and dicarboximide fungicides against Botrytis cinerea in several in vitro bioassays. Kor. $J$. Pest. Sci. (in Korean) 3:37-44.

Choi, G. J., Jang, K. S., Choi, Y. H. and Kim, J. C. 2009a. Control efficacy of a new fungicide fludioxonil on lettuce gray mold according to several conditions. Res. Plant Dis. (in Korean) 15:217-221.

Choi, G. J., Kim, J. C., Jang, K. S., Nam, M. H., Lee, S. W. and Kim, H. T. 2009b. Biocontrol activity of Acremonium strictum BCP against Botrytis disease. Plant Pathol. J. 25:165-171.

Choi, I. S., Chung, Y. R. and Cho, K. Y. 1995. Variations in phenotypic characteristics, pathogenicity and fungicides resistance of Botrytis cinerea, gray mold rot fungus, isolated from various plants. Kor. J. Mycol. (in Korean) 23:246-256.

Chung, J. W., Lee, C. Y., Yun, S. C. and Cho, K. Y. 2008. Screening of myxobacteria inhibiting the growth of Collectotrichum acutatum causing anthracnose on pepper. Kor. J. Microbiol. Biotechnol. (in Korean) 36:21-27.

Dawid, W. 2000. Biology and global distribution of myxobacteria in soils. FEMS Microbiol. Rev. 24:403-427.

El-Ghaouth, A., Smilanick, J. L., Brown, G. E., Ippolito, A. and Wilson, C. L. 2001. Control of decay of apple and citrus fruits in semi-commercial tests with Candida saitona and 2-deoxyD-glucose. Biol. Cont. 20:96-101.

Gerth, K., Pradella, S., Perlova, O., Beyer, S. and Müller, R. 2003. Myxobacteria: proficient producers of novel natural products with various biological activities - past and future biotechnological aspects with the focus on the genus Sorangium. J. Biotechnol. 102:233-253.

Hang, N. T. T., Oh, S. O., Kim, G. H., Hur, J. S. and Koh, Y. J. 2005. Bacillus subtilis S1-0210 as a biocontrol agent against Botrytis cinerea in strawberries. Plant Pathol. J. 21:59-63.

Hjeljord, L. G., Stensvand, A. and Tronsmo, A. 2001. Antagonism of nutrient-activated conidia of Trichoderma harzianum (atroviride) P1 against Botrytis cinerea. Phytopathology 91:11721180.

Hyun, H. S., Chung, J. W., Lee, H. B., Youn, J. K., Lee, C. Y. Kim, D. H. and Cho, K. Y. 2009. Isolation of cellulose-degrading myxobacteria Sorangium cellulosum. Kor. J. Microbiol. (in Korean) 45:48-53.

Kim, B. S., Anh, J. W. and Cho, K. Y. 1998. Isolation and identification of myxobacteria KR025 and searching of their bioac- tive compounds. Kor. J. Plant Pathol. 14:345-349.

Kim, H. H. and Son, S. Y. 2001. Identification and characterization of myxobacteria from Korean soil. Kor. J. Microbiol. (in Korean) 37:239-244.

Kim, J. H., Lee, S. H., Kim, C. S., Lim, E. K. Choi, K. H., Kong, H. G., Kim, D. W., Lee, S. W. and Moon, B. J. 2007. Biological control of strawberry gray mold caused by Botrytis cinerea using Bacillus licheniformis N1 formulation. J. Microbiol. Biotechnol. 17:438-444.

Kim, S. K., Choi, B. H., Kim, J. G., Lee, B. K. and Kang, H. I. 2003a. Isolation of myxobacteria from soil and RFLP analysis of 16S rDNA fragments. Kor. J. Microbiol. (in Korean) 39:187-191.

Kim, S. T. and Yun, S. C. 2011. Biocontrol with Myxococcus sp. KYC 1126 against anthracnose in hot pepper. Plant Pathol. J. 27:156-163.

Kim, Y. S., Bae, W. C. and Baek, S. J. 2003b. Bioactive substances from myxobacteria. Kor. J. Microbiol. Biotechnol. (in Korean) 31:1-12.

Krug, D., Zurek, G., Revermann, O., Vos, M., Velicer, G. J. and Müller, R. 2008. Discovering the hidden secondary metabolome of Myxococcus xanthus: a study of intraspecific diversity. Appl. Environ. Microbiol. 74:3058-3068.

Kulakiotu, E. K., Thanassoulopoulos, C. C. and Sfakiotakis, E. M. 2004. Postharvest biological control of Botrytis cinerea on kiwifruit by volatiles of 'Isabella' grapes. Phytopathology 94:1280-1285.

Lee, N. Y., Kwon, E. M., Kim, J. C. and Yu, S. H. 2004. Biological control of Botrytis leaf blight of lily and Botrytis gray mold of cucumber by Ulocladium atrum. Res. Plant Dis. (in Korean) 10:319-323.

Lee, S. W., Kim, J. h., Min, J. Y., Bae, Y. S. and Kim, H. T. 2007. Monitoring for the resistance of Botrytis cinerea causing ginseng gray mold to procymidone and its multiple resistance with the mixture of carbendazim/diethofencarb. Res. Plant Dis. (in Korean) 13:170-176.

Leibinger, W., Breuker, B., Hahn, M. and Mendgen, K. 1997. Control of postharvest pathogens and colonization of the apple surface by antagonistic microorganisms in the field. Phytopathology 87:1103-1110.

Niggemann, J., Michaelis, K., Frank, R., Zander, N. and Höfle, G. 2002. Natural product-derived building blocks for combinatorial synthesis. Part 1. Fragmentation of natural products from myxobacteria. J. Chem. Soc., Perkin Trans. 1:2490-2503.

O’Neill, T. M., Niv, A., Elad, Y., and Shtienberg, D. 1996. Biological control of Botrytis cinerea on tomato stem wounds with Trichoderma harzianum. Eur. J. Plant Pathol. 102:635-643.

Park, S. M., Kim, H. S. and Yu, T. S. 2006. Antifungal activity of Bacillus sp. KMU-1011 against gray mold causing Botrytis cinerea. Kor. J. Microbiol. Biotechnol. (in Korean) 34:63-69.

Park, S. Y., Lee, B. S., Kim, J. H., Lee, C. Y., Jang, E. H. and Cho, K. Y. 2004. Isolation and characterization of bacteriolytic wild myxobacteria. Kor. J. Microbiol. Biotechnol. (in Korean) 32: 218-223.

Paulitz, T. C. and Bélanger, R. R. 2001. Biological control in greenhouse systems. Annu. Rev. Phytopathol. 39:103-133. 
Reichenbach, H. 2001. Myxobacteria, producers of novel bioactive substances. J. Ind. Microbiol. Biotechnol. 27:149-156.

Reichenbach, H. and Höfle, G. 1994. Discovery of a new antifungal mechanism of action: soraphen - an almost-success story. Scientific Annual Report, Gesellschaft für Biotechnologische Forschung mbH. Braunschweig, pp. 5-22.

Sharma, R. R., Singh, D. and Singh, R. 2009. Biological control of postharvest diseases of fruits and vegetables by microbial antagonists. Biol. Cont. 50:205-221.

Son, Y. J., Lee, J. P., Kim, C. S., Song, J. H., Kim, H. J., Kim, J. W., Kim, D. H., Park, H. C. and Moon, B. J. 2002. Biological control of gray mold rot of perilla caused by Botrytis cinerea $\mathrm{I}$. resistance of perilla cultivars and selection of antagonistic bacteria. Plant Pathol. J. 18:36-42.
Soung, M. G. and Sung, N. D. 2007. CoMFA and CoMSIA analysis on the selective fungicidal activity of $\mathrm{N}$-phenyl- $\mathrm{O}$-phenylthionocarbamate analogues against resistant and sensitive gray mold (Botrytis cinerea). Kor. J. Pest Sci. (in Korean) 11: 138-143.

Tian, S., Fan, Q., Xu, Y. and Liu, H. 2002. Biocontrol efficacy of antagonist yeasts to gray mold and blue mold on apples and pears in controlled atmospheres. Plant Dis. 86:848-853.

Williamson, B., Tudzynski, B., Tudzynsk, P. and Van Kan, J. A. L. 2007. Botrytis cinerea: the cause of grey mould disease. Mol. Plant Pathol. 8:561-580.

Xi, L. and Tian, S. P. 2005. Control of postharvest diseases of tomato fruit by combining antagonistic yeast with sodium bicarbonate. Sci. Agri. Sinica 38:950-955. 